\title{
The perception of the values of urban space by senior citizens of Valparaiso
}

\author{
Giulietta Fadda $^{\mathrm{a}, *}$, Alejandra Cortés ${ }^{\mathrm{b}, 1}$, Alessandra Olivi ${ }^{\mathrm{c}}$, Marcela $\operatorname{Tovar}^{\mathrm{d}}$ \\ a Department of Architecture, Universidad de Valparaiso, Avenida Matta 40, Recreo, Viña del Mar, Chile \\ ${ }^{\mathrm{b}}$ Department of Architecture, Universidad Federico Santa María, Avenida España 1680, Valparaiso, Chile \\ c Instituto de Desarrollo Regional, Universidad de Sevilla, Spain \\ d International Consultant, City University of New York (CUNY), New York, NY, United States
}

\section{A R T I C L E I N F O}

\section{Article history:}

Received 18 March 2009

Received in revised form 11 June 2009

Accepted 10 July 2009

\section{Keywords:}

Quality of life

Aging population

Spatial demography

Heritage city space perception

Neighborhood

Social networks

\begin{abstract}
A B S T R A C T
This paper is framed within the context of the Fondecyt Research Project (No. 1061179) entitled "Senior Citizens' quality of life in an Urban Habitat: Valparaiso, a Case Study." It investigates how certain topographical conditions in the urban habitat impact on the quality of life of the population's most senior age group. Following a theoretical approach, we discuss some of the initial results obtained in our field research, integrating a quantitative technique of territorial analysis, GIS maps, and the qualitative techniques of Focus Groups and ethnographic interviews. The study of senior citizens' perceptions of their quality of life in Valparaiso indicates that the city's irregular topography and character as a heritage city mediate how the elderly perceive the urban space, creating social networks and a sense of community uniquely their own.
\end{abstract}

(c) 2010 Elsevier Inc. All rights reserved.

\section{Introduction}

Population aging is one of the great demographic transformations of our era. The quantitative increase of senior age groups is not only a part of demographic evolution; it is also an important social change that has consequences for our way of understanding and thinking the city. In this sense, it is important to consider that aging is a social phenomenon and not a problem, meaning that its consequences for society as a whole must be evaluated. A variety of challenges have emerged in urban contexts that have to do with building cities that are integrative of older people, leading to a shift toward new priorities, among them the creation of an urban environment that is propitious and favourable for aging. The challenge is thus one of building cities and neighborhoods that are senior friendly and inclusive.

\footnotetext{
* Corresponding author. Tel.: +56 32 2621666; fax: +56 322477033.

E-mail addresses: gfadda@vtr.net (G. Fadda), alejandra.cortes@usm.cl (A. Cortés), alessandraolivi@idr.es (A. Olivi), mtovar1967@yahoo.com (M. Tovar).

${ }^{1}$ Tel.: +5632 2654106 .
}

This article presents some results of the Fondecyt Research Project (No.1061179) entitled "Quality of Life of the Senior Citizen in an Urban Habitat: Valparaiso, a Case Study," which were obtained through an integrated methodological approach. These results refer to this age group's perceptions of their quality of life, in reference to their urban environment and social networks.

In carrying out our study of senior citizens and their relationship to Valparaiso's urban habitat, we applied the notion of quality of life-a multidimensional concept of great validity for evaluating the living conditions and well-being of social groups within a specific environment.

The concept of quality of life provides the theoretical and methodological basis of this research. It is an eminently evaluative or value-related concept, capable of including a wide range of phenomena (both objective and subjective), and is effective for assessing the circumstances and well-being of social groups in their habitat.

The article is structured in four parts: (1) a description of the demography of aging highlights its importance in cities in industrialized and less- industrialized countries. Here Valparaiso is contextualized within the Chilean and Latin American 
age shifts. (2) Conditions that affect Valparaiso's spatial configuration are explained in relation to the quality of life of older adults, exploring the notion of neighborhood. (3) Partial results obtained during the fieldwork research are presented and classified under two types of senior citizen perceptions: (a) social networks associated to geographical and spatial conditions, and (b) the perception of the urban habitat as a World Heritage Area. Finally, (4) conclusions and policy recommendations are presented.

\section{Demography of aging: North-South trends}

The aging of the population is a dramatic demographic shift that is taking place in both industrialized and less-industrialized countries. By 2050, an estimated 22\% of the world's population will be over sixty years old, and for the first time in history there will be more seniors than children. This means that in many world cities, one person in four will be a senior, thus changing our urban scenarios (Lorinc, 2008). Illustrative examples of this shift in industrialized countries are France, Spain, Japan and the United States, where age projections for 2050 show that more than $30 \%$ of their populations will be above 60 years of age.

For the period from 2025 to 2050, projected figures for France, Japan and Spain (Table 1) show that while the youngest percentage of the population will decrease slightly or, in Japan's case, will remain practically free of variation the population older than 60 years will experience a sharp percentage increase, especially in Spain's case, where a total rise of more than 9 percentage points is recorded.

Similar numbers are presented by Burnett (2008) for the U. S. case. Here projections establish that, according to the Census Bureau, by 2030 out of a total population of 300 million, 70 million will be older than 65 . People aged 65 years or older accounted for just $13 \%$ of the population in 2000 . This shift will be sustained not only by the entry of the baby boomers into the $65+$ age span, but by increasing longevity and declining fertility. By 2050, the percentage of the population in the U.S. aged 65 and older is expected still to be 20.4\% (Burnett, 2008).

In this demographic scenario, industrialized countries have implemented different policies and solutions to respond to the age gap between generations in the economic and social arenas. Aging has become an important issue in government agendas and policy makers carefully consider its implications for health care and pension systems, as well as for housing, transport and mobility planning and projects designed to specifically address seniors' needs.

A general comparison between cities in the less-industrialized South and those in the industrialized North show that

Table 1

France, Japan and Spain Age Projections.

\begin{tabular}{llllll}
\hline & 2025 & & & 2050 & \\
\cline { 2 - 3 } \cline { 5 - 6 } & $0-14$ years & $\geq 60$ years & & $0-14$ years & $\geq 60$ years \\
\hline France & 17.2 & 28.1 & 16 & 31.4 \\
Japan & 13.5 & 32.9 & & 13.6 & 37.6 \\
Spain & 15 & 21.2 & & 14.1 & 30.8 \\
\hline
\end{tabular}

Sources: Lorinc, 2008; Instituto Nacional de Estadística España (http://www. ine.es); Organization for Economic Co-operation and Development, 2005 (www.oecd.org). the latter have better subsidies for older adults, superior social security and pension systems, as well as more adequate infrastructure and housing for this age group. Madrid, New York and Paris are good examples of cities where aging policies have been implemented.

An illustrative case is that of the Spanish government, which has made interesting efforts to implement the Madrid International Action Plan on Aging (Plan de Acción Internacional de Madrid sobre el Envejecimiento) in various cities, including Madrid and Barcelona. Aging has been integrated as an important issue in the government's gender equity policy, health system and subsidies. The city of New York has implemented special housing, transport and food programs for seniors in recent decades, while Paris has made similar efforts to improve its aging policies since 2004, when its mayor launched a city program called "Les initiatives de la bientraitance." This program aims to protect aging persons from mistreatment (also a very important issue in aging policy), and to promote various initiatives geared toward providing services and better quality of life for aging persons (ActivAge Consortium, 2004).

Nevertheless, in less-industrialized countries where population aging is likewise imminent, differences in economic, institutional and historical circumstances mean that the experience of industrialized countries does not offer easilyreproducible solutions for the problems their cities also face.

The Madrid International Action Plan (Naciones Unidas, 2002) outlined the challenge faced by cities as a result of the global trend of population aging, of building societies that will integrate their senior citizens. That is, a society that would be functional in terms of the participation of the elderly; recognition of their potential for making economic, social and cultural contributions; expansion of their activities and social inclusion; ties of inter-generational solidarity at the family and community levels; eradication of poverty; and consolidation of a healthy culture of aging, emphasising the prevention of health issues and risks that are characteristic of this life stage. As mentioned before, one of the Madrid Plan's high-priority guidelines is the implementation of a favourable environment for aging. To this end, the Plan encourages the development of senior citizen-friendly neighborhoods and cities. This implies that a study of the situation of senior citizens in large cities should be the first priority, so that all improvements in this regard may be possible to implementin urban design and the equipping of public spaces, as well as the restructuring of urban space.

Likewise, the Brown Agenda (Bartone, Bernstein, \& Leitmann, 1992) has referred directly to the urgent need for sustainable cities that strengthen the reciprocal relationship between today's generations and that move in the direction of progress without compromising the future of the generations to come. Sustainability implies integration within the city of the social, ecological and economic processes that make up local development and the enhancement of all age groups' quality of life.

In Latin America, the population is aging more rapidly than was historically the case in what are now the industrialized countries. Furthermore, aging is taking place in contexts characterized by pervasive inequality, inadequate institutional development, low-quality social protection systems with incomplete coverage, and excessively-burdened families who 
must not only meet the needs of the elderly, but also fill the gaps left by the near-absence of other social institutions that ought to act as a force for social protection and cohesion (Celade, 2007).

In all countries in the region, the proportion and absolute number of people aged 60 and over will increase. "In absolute terms, it is expected that there will be 57 million more adults by 2025 in addition to the 41 million in 2000, and an increase of 86 million is expected between 2025 and 2050. This is a population that is growing rapidly (at an average annual rate of $3.5 \%)$, more so than cohorts of younger ages. The rate of growth will be three and five times as great for this population as for the total population in 2000-2025 and 2025-2050, respectively. Because of this dynamic, the segment of the total population comprised of persons aged 60 years or older will triple between 2000 and 2050. Thus, by the end of this period, one in four inhabitants of Latin America and the Caribbean will be an older person" (Celade, 2007, pp. 7-8).

As for the general characteristics of Latin America's future adult population, despite the existing differences between the countries, projections indicate that older adults will be predominantly women (with 116 women aged 60 and older for every 100 men), and the great majority will live in urban areas.

Chile and Uruguay are aging more rapidly than other countries in the region, following an aging pattern similar to that of industrialized countries such as France.

The numbers for Chile show that the population of older adults increased sevenfold in the twentieth century, and that this figure will double within the next 21 years. This age group has the fastest growing rate in the country and represents $11.4 \%$ of its total population. Projections estimate that by 2035 there will be more seniors than young people (INE, 2000). Chackiel (2000) states that by 2050, 19.7\% of the population will be between 0 and 14 years old, and $23.5 \%$ will be between 60 years and older.

In the Chilean context Valparaiso is one of the cities with the highest aging rates According to the latest Census, taken in 2002, senior citizens make up $11.4 \%$ of Chile's total population, while in the district of Valparaiso they comprise $13.94 \%$ of the population, of which $40.3 \%$ are males and $59.7 \%$ females.

The significant numbers of senior residents in Valparaiso, together with its peculiarities insofar as topography and urban development are concerned, have been the motivating factors for choosing this city in order to study in depth the relationship between urban habitat and quality of life of the population's oldest age group. We posit that Valparaiso represents a particularly interesting subject of study, since: Valparaiso's population has the highest aging rate of the three most important Chilean cities; topography has been a defining element in Valparaiso's urban configuration and developmental process; and Unesco recently declared the city a Patrimony of Humanity.

\section{A theoretical approach to the context of Valparaiso}

Cities, like any human product, are the faithful reflection of the societies that produce them and their habitat conditions determine many of their residents' opportunities for development and well-being.

Valparaiso, the city that is our object of study, has certain characteristics that may prove to be either advantageous or disadvantageous for the urban integration of its senior citizens. It is a coastal town invested with a rich patrimonial and cultural character, a peculiar topography and an emergent real estate dynamic.

Valparaiso was recently declared a World Heritage City (July 2003). This has increased the inflow of tourism and of public, private and mixed investments and boosted the city's renovated image. This development has also caused land values in the heritage areas to rise, generating a significant process of gentrification. The latter phenomenon, as Sargatal (2001) explains, is characterized by the residential occupation of urban centers by the upper classes, which displace the original lower-income residents, including senior adults.

In spite of the above, the development of global cities with cultural potentialities, as is Valparaiso's case, opens up opportunities for an exceptional quality of life for its inhabitants, on condition that they succeed in making correct use of their resources and containing the negative effects associated with short-term opportunistic dynamics, in order to promote the development of a friendly, inclusive and sustainable city.

Within this perspective, one of our main research objectives was to investigate which aspects bring about improvement or deterioration of the quality of life of Valparaiso's senior citizens. Quality of life represents an aspect of great importance for human beings: it is a concept that is difficult to define and measure because of the elements that must be applied for its determination. Generally it is associated with quantitative conditions in the environment, excluding everything that emanates from both the social relationships made possible by given environments, and the expectations of development and the perceptions of individuals. Nevertheless, all these elements are inherent in a more contemporary reading of the term 'quality of life'.

Quality of Life is closely linked to the functioning of society, with the norms and social values that the individual must assume, but above all, with the individual's aspirations and their degree of satisfaction in relation to the most important dominions in which he/she develops his/her life" (Victoria García-Viniegras, 2008, p. 112). The concept of Quality of Life arises toward the 1970 s as a reaction to the economicist and quantitative criteria employed in "social reports" or studies on standards of life. The OECD established for the first time in 1970, "the need to insist that economic growth is not an end in itself, but an instrument for the creation of improved conditions of life, and for this reason emphasis must be placed on its quality aspects" (Rueda, 1998). This logic situates the problem beyond the limits of a merely technocratic proposal.

Nevertheless, many attempts to approach quality of life have been restricted to the study of objective conditions of the surroundings, excluding those related to the social or cultural relations, the development expectations and the perceptions of the individuals of their own quality of life. These are indispensable conditions for a comprehensive and actualised conception of the notion of quality of life. From this comprehensive perspective, the concept of quality of life represents something more than a private "life level" and it is referred to all the elements of the conditions in which people live, all their needs and satisfiers.

The notion of quality of life encompasses aspects of welfare and of wealth that are material and non-material, objective and subjective, individual and collective. According to Moyano and 
Ramos (2007), “...Its objective dimension refers to an availability of goods and services for each one, while the subjective dimension refers to the valuation of these in relation to one's own life." For Ardila (2003), good quality of life implies “...a state of general satisfaction, derived from the fulfillment of a person's potentialities.... It is a subjective feeling of physical, psychological and social well-being." He includes as subjective aspects: intimacy, emotional expression, perceived safety, personal productivity, and perceived health. As objective aspects of material well-being: harmonious relations with the physical and social environment and with the community, and objectively perceived health." This concept is therefore a tool of great validity and potential for the study of the quality of life of social groups in their habitat. Its application determined, to a great extent, the methodology employed, not just in the Focus Groups, but in each of the other instruments as well.

The concept of quality of life is understood as a social construction or a constructed object which does not exist except through the observer and her or his own experience. It is not a set of material conditions. It is not the mere satisfaction experienced by an individual but, rather, a dialectic between what is being observed by two actors: one who observes the observations of the one who observes her/his experience.

Quality of life in old age poses serious challenges in terms of conceptual development and practical application. Our study proposes the idea that habitat is a fundamental variable given that it can influence a set of factors such as: feelings of safety and social integration, the accessibility of family and social support networks, physical isolation, use of leisure time, and seniors' community spaces. This enables us to sustain that habitat may be approached as a tool for fomenting the quality of life of older adults.

As previously mentioned, Valparaiso's habitat is characterized by its peculiar topography. Although the city is comprised of a diversity of unique sectors, each with its highly individual characteristics, it possesses a distinctive unity. The urban layout, which borders a bay with a northward orientation, is perched upon a narrow coastal plain surrounded by 42 hills that form an amphitheater, overlooking the sweeping vista of the Pacific Ocean. Two large sectors can be distinguished: one is the plain (El Plan), or downtown area, and the other, the hills (Cerros) (Fig. 1). Valparaiso's topography has been a determining element for its urban configuration and development process (Map 1). It has conferred very unique characteristics to its public spaces: a large number of its Bstreets, alleys, avenues, stone steps and terraces are wide balconies or belvederes that overlook the bay and ocean (Fig. 2).

These characteristics have influenced Valparaiso's urban configuration and its residents' quality of life. Some results obtained in our interviews and focus groups highlight the significant, intimate relationship between older adults' quality of life, Valparaiso's special geographical conditions, territorial appropriation, and the social experience of age connected to spatiality. This relationship cuts across many of our informants' narratives of the different ways they experience the city and how it is interlinked to their own appreciations of quality of life.

Our ethnographic record shows that, contrary to other age groups, older adults constantly use the category of neighborhood as a referent to explain their relationship with the urban environment, and the social relations that they can or cannot establish as citizens in Valparaiso. For this reason, the notion of neighborhood has been adopted as an analytical category in this research.

According to Wellman (1996) there are two levels of analysis in the relationship between territory and personal networks that address differing objectives. Researching who the subjects are, where significant persons for the subjects live, and reconstructing individuals' interactions, can yield contrasting results. While the subjects' significant networks in urban contexts are diffuse and dispersed, extending outward in a personalized and highly diversified manner beyond the local context, in daily interaction one may still be able to register the juxtaposition between personal networks and the neighborhood context. The importance of spatial proximity in personal relationships is particularly valid for the categories of persons with reduced mobility and who bear the burden of distance-one of them being the category of senior adults. In many cases, for them the neighborhood continues to represent their principal environment for living and for social relations.

For this reason, even if is possible to find different spatial and political divisions in the city, we have nonetheless chosen to explore the category of neighborhood, given its importance for older adults. For this age group, the notion of neighborhood is an essential one for their construction of individual and collective age identity.

Gravano (2003) identifies various features linked to the neighborhood category that figure in our informants' accounts regarding their own social construction of space. Here the delimitation of a neighborhood implies more-or-less defined or imprecise physical and/or symbolic limits, which

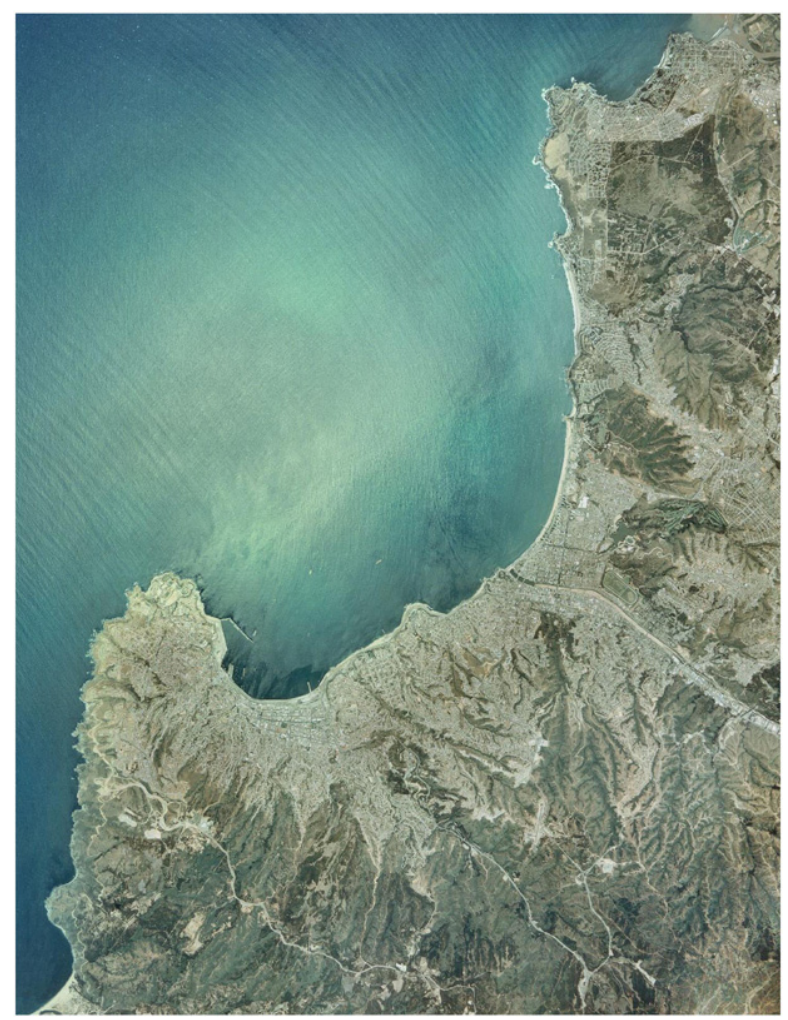

Fig. 1. Aerial photograph of Valparaiso. 


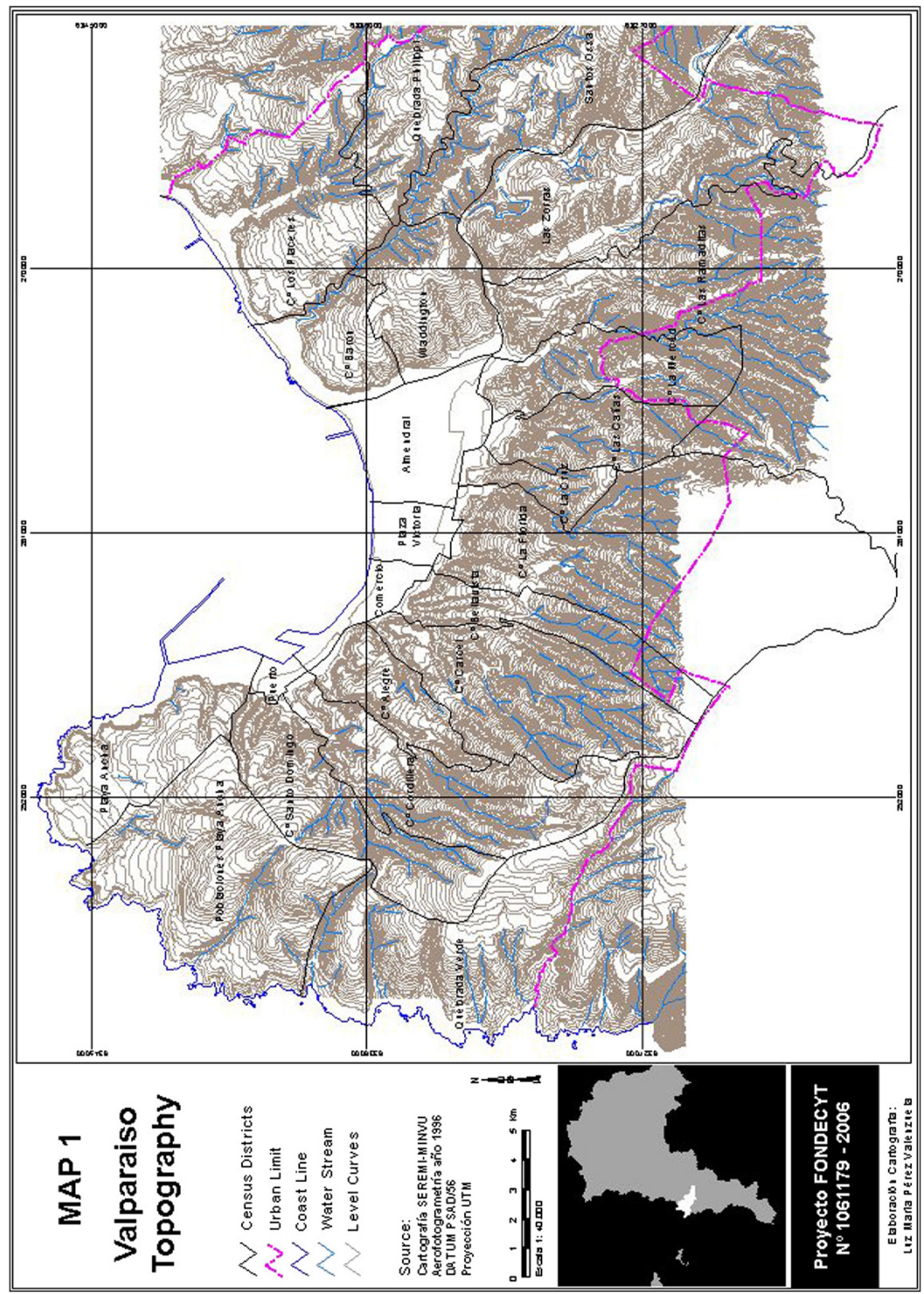

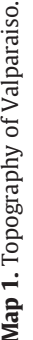




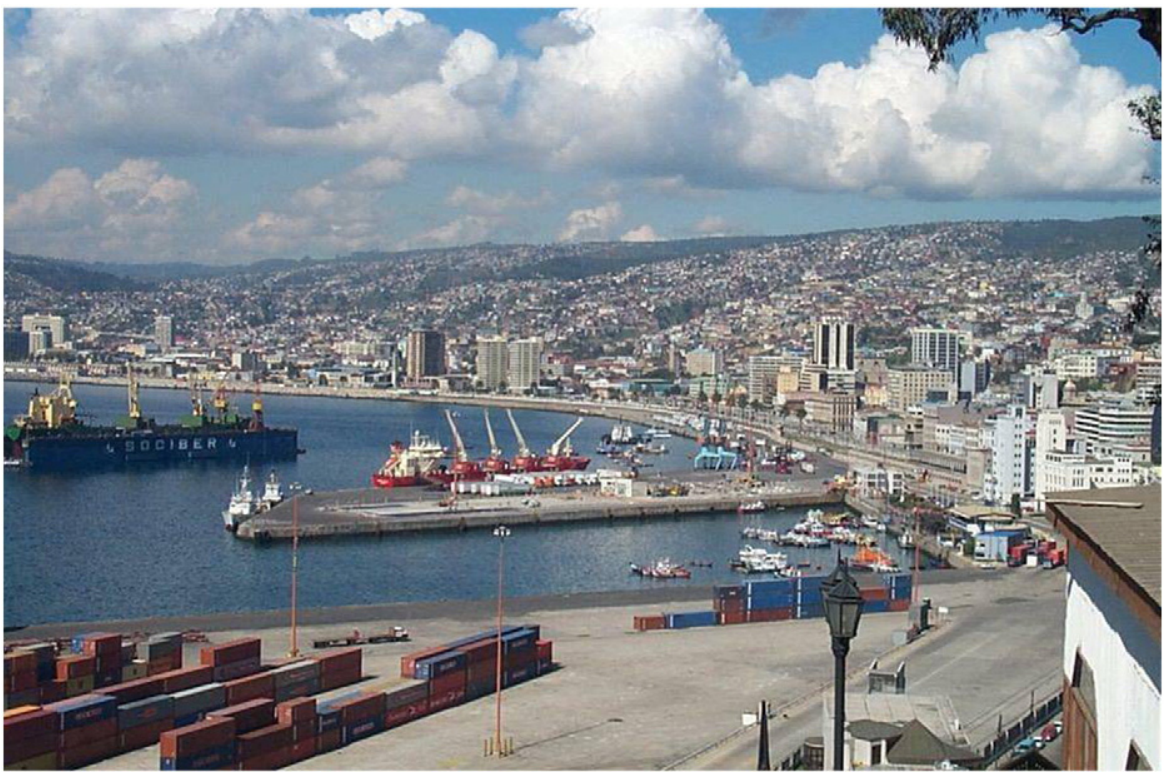

Fig. 2. Panoramic photograph of Valparaiso.

do not necessarily coincide with administrative boundaries. It also involves topographical and/or administrative factors, along with other sociological realities such as primary, noninstitutional, spontaneous and inclusive relationships. Notions of closeness and familiarity have great importance, although there are limits created by roadways, which usually do not coincide with those drawn in the older adult's consciousness.

In this sense, the neighborhood cannot be defined solely by spatial, ecological or natural categories, nor by physical conditions, as an exclusively physical unit. Rather, it can be defined by its symbolic and identifying character.

A neighborhood is characterized by having "its own personality," forming a "family of families" and representing a "microcity." From this perspective, it constitutes a step between the city and the individual; it is a perfectly known, familiar space, felt as "their own" by its residents through their personal and social perceptions. It is also functional and mainly residential. The respective neighborhood is limited to areas within easy reach of pedestrians, allowing each area to be a sociological reality based on the notion of proximity and vicinity.

The ideas on the relationship of the senior adult with their own community and physical space have had a complex history in social gerontology and community studies. One interesting line of investigation points to the development of the neighborhood dimension in studies on older adults (Phillipson, 2007), conceptualising three dimensions of habitat that seniors maintain bonds with, and through which they build networks (Phillipson, Bernard, Phillips, \& Ogg, 2001). 'Neighbors' are the persons who live in the vicinity of other persons; the 'neighborhood' is the territory of the locality effectively inhabited by the neighbors, and 'neighboring' is the mode of interaction within the neighborhood.

Proximity is the key attribute of these relationships, and, in point of fact, the scope of the area within which these concepts operate, in most cases, does not extend beyond the street, the city block or the building.

\section{Main research results}

In order to uncover all the above-mentioned aspects in our research, a comprehensive methodology was applied to discover the close relationship that exists between the elemental physical and social aspects. We will thus be able to evaluate the quality of people's lives only if, in addition to objective data, the observers' expertise and subjective experiences are also included (Fadda \& Jiron, 1999). This implies that studies on quality of life should employ methodologies that cover its objective as well as its subjective elements.

In order to validly and profoundly address the wide scope and complexity of quality of life, the triangulation approach was used; that is, an analysis combining several quantitative and qualitative methodological instruments. Such methods include the GIS system for georeferencing demographic data from the 2002 Census to maps of Valparaiso, the Focus Groups directed at the players themselves, the Delphi Survey for collecting opinions of experts in the field, senior citizen surveys, interviews, field observation, bibliographic reviews and so on.

The above conceptualization and analysis of the city's topography provides us with the basis for formulating a proposal for Valparaiso's subdivision into 97 neighborhoods (Fadda \& Cortés, 2007) (see Map 2), and constitutes an organising instrument in the surveying and compiling of qualitative and quantitative information. Based on the data from GIS maps, urban areas with the highest numbers of senior residents were identified. The selection criteria combined place of residence (the plain vs. the hills) and socioeconomic differences (the most and least vulnerable) among the older adults. Focus Groups and interviews were conducted in the plain area: in the Almendral Sector and the Commerce Sector; and in the hills: Cerro Barón and Cerro Alegre (see Map 3).

The Focus Group is a communicative experience that favours the construction of collective meanings, on the basis of the participants' subjective vision. The subjects therefore contribute, with their own perceptions and visions, pertinent 


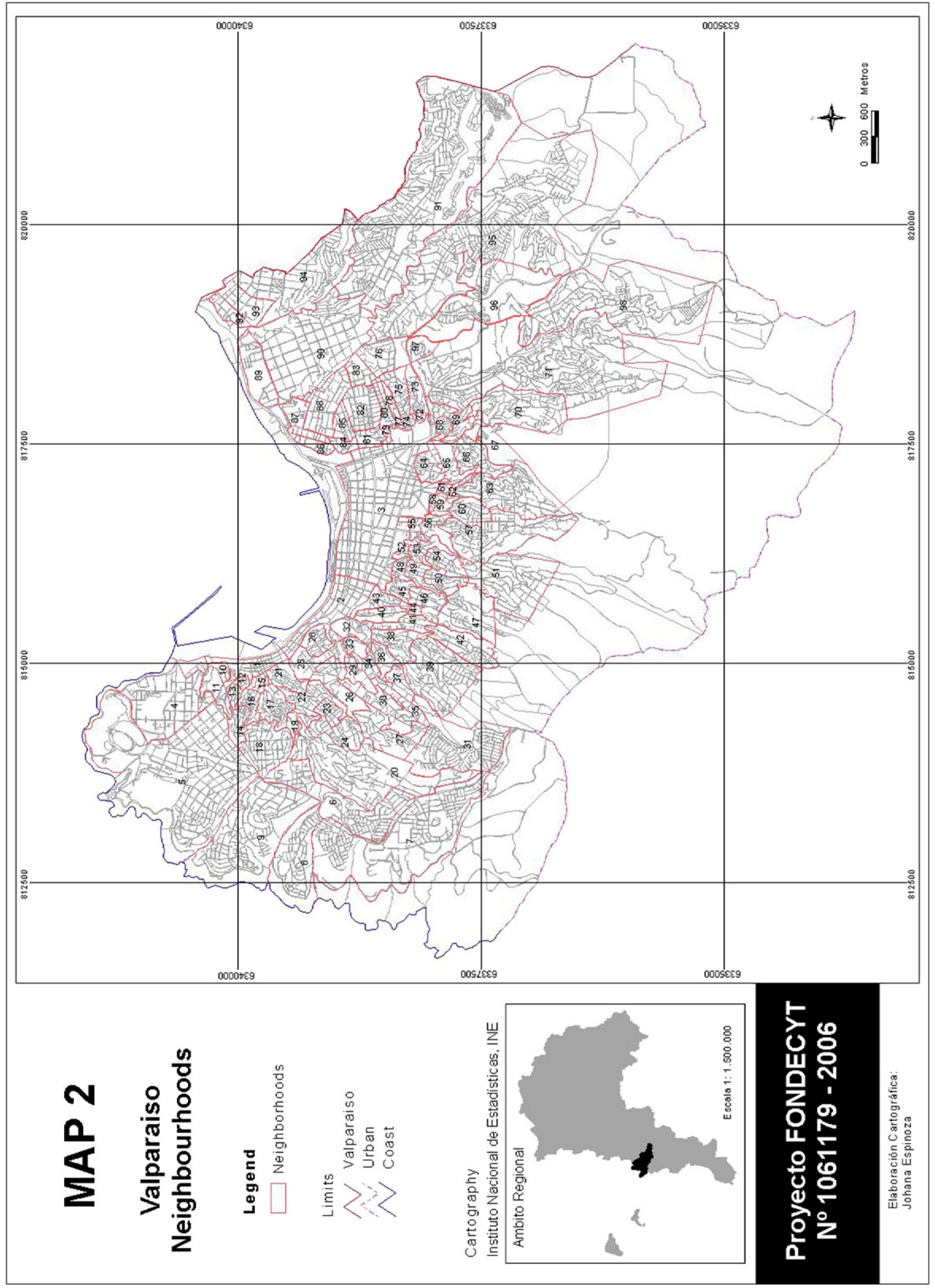




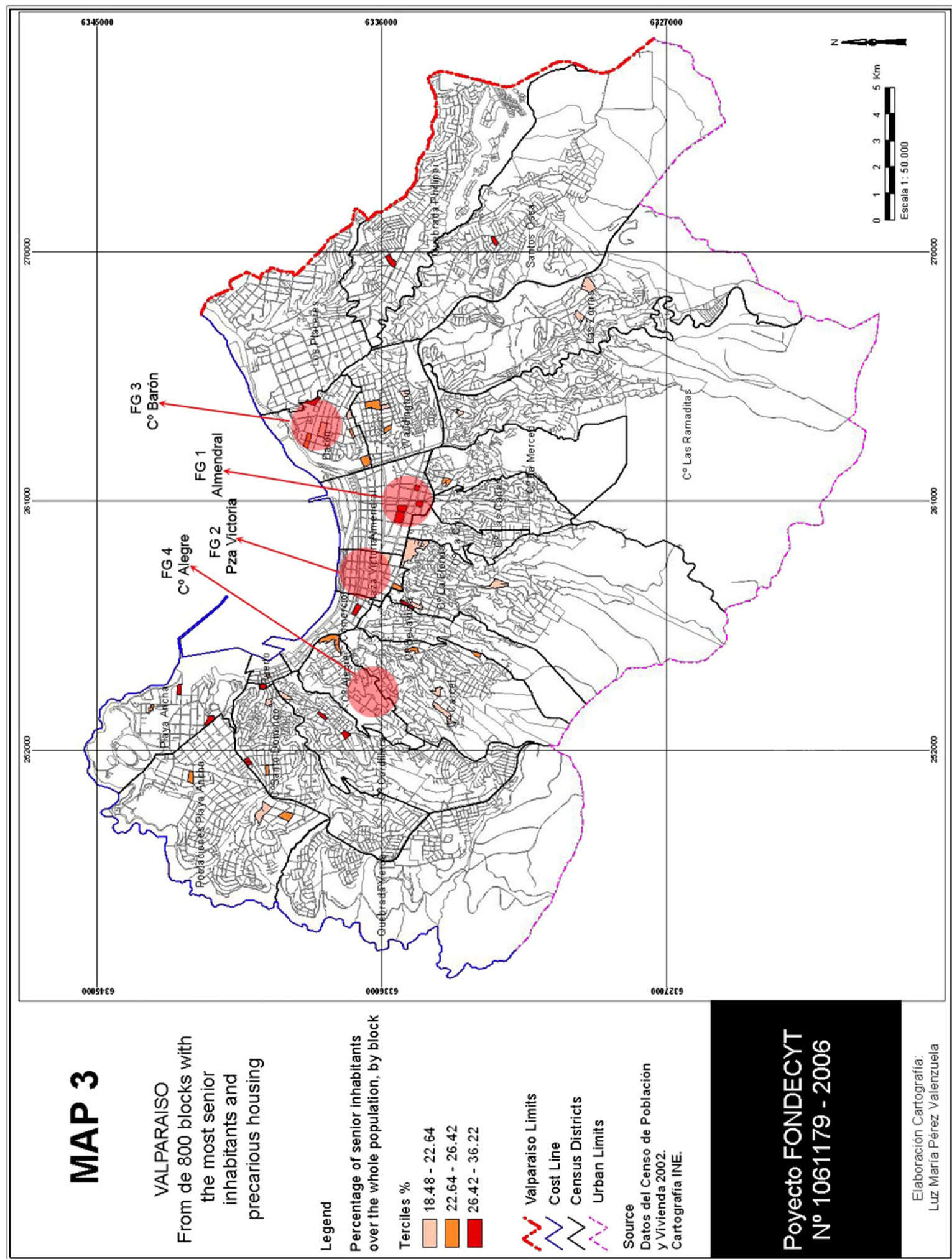

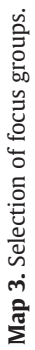


and significant knowledge in conceptual and terminological terms. It constitutes an experience of group conversation that is indicative of consensus and divergences among sectors having similar characteristics. It thus follows that, in the selection of the participants, not only must socio-demographic or population criteria be considered, but chiefly sociocultural, psychosocial, communicational and experiential processes of the collectives or social groups under study. Through this group dynamic, the identification was sought of the main elements that the participants considered to be important or defining of their quality of urban life. In the present document, the stories are transcribed verbatim (in italics), followed by parentheses containing the data on the narrator's sex and the sector where the Focus Group work was carried out.

The sampling of focal groups is intentional and, in this case, the selection method was based on the criteria established in the project's main proposals, as follows: (a) Population sectors located in the zones of the plain and the hills having a greater concentration of older adults; and (b) different socioeconomic groups.

During the first level of approximation for territorial selection of the groups, 2002 Census data were used pertaining to socio-demographic criteria that were selected and correlated in accordance with the research project's objectives. This information was geo-referenced in the cartographic base of the city of Valparaiso, resulting in 21 thematic maps.

In addition, for the selection of the group participants, their socioeconomic status was considered. This, inasmuch as it was of interest to contrast the opinions of the most vulnerable groups with those of other, less vulnerable ones.

In synthesis, for the selection of the sampling, criteria were adopted of population density of older adults by zones of Valparaiso, of socioeconomic differences reflected in housing quality, of ecological zones and localization in different neighborhoods of the city (plain/hills).

The sample was made up of four focal groups, selected on the basis of the criteria of typical cases established as population sectors located in the zones of the plain and of the hills, with high proportion of adults from varying socioeconomic groups (see Map 3), in which an average of 10 older adults per group took part. To ensure maximum heterogeneousness within the homogeneity, an effort was made to respect a certain degree of gender parity among the members.

The questions revolved around three main themes: (1) perception of aging; (2) perception of the urban habitat (relationship with the physical environment: one's dwelling, neighborhood, city); and (3) perception of social networks (relationship with one's significant environment: formal and informal networks). The modes used for data collection were video, notes and audio recordings.

The in-depth interviews were semi-structured, aimed at key informants, informal narrations and dialogs with Valparaiso residents, participant observation, and the data were recorded in field notes and photographic and film records of the main stages of information gathering.

The informant selection criteria were the same as those for the Focus Groups and the delimitation of the universe of respondents for the survey, and basically correspond to: (1) density of older adults by urban stratum; (2) residence in the plain sector and in the hills; (3) differences in socioeco- nomic condition (vulnerable/stable) and (4) third and fourth age ( $>65$ and $>75$ ).

The universe of the study is composed of 27 older adults (13 women and 14 men), who were interviewed in depth at least once. The average duration of the interviews was 1 hour, in some cases carried out in various stages.

The results obtained can be classified according to two types of senior citizen perceptions regarding their quality of life: (a) social networks associated to geographical and spatial conditions, and ( $b$ ) the perception of the urban habitat as a world heritage area. A brief overview follows of the principal evaluations and perceptions of seniors with respect to these categories. The narratives were extracted from the Focus Group and interview records.

\section{Social networks}

Research outcomes have made evident the significant importance of social networks in elders' quality of life, and the role spatial conditions play in their constitution. As different authors have stated (Appadurai, 1996; Segato, 2005; Soja, 1989; Zukin, 1992) space and territory can be considered as constitutive elements of social networks that produce collective and individual age group identities. Processes like place making and spatial appropriation, mediate the objective and subjective perception older adults have of their own age as well as their quality of life. We were able to identify key elements such as accessibility, mobility and spatial segregation, which intervene in elders' use and experience of space within the particular topographical conditions of Valparaiso. These differences are referred to the hills/flat areas of the city which seem to influence in a distinct manner the way older adults can structure their social networks.

In order to spatially represent the weave of their social networks, older adults constantly refer to the dimensions of the hill and the plain as two levels that are clearly differentiated through physically- and socially-definable limits and borders, which seem to distinctly influence how older adults are able to structure their social networks.

"Often I'm asked, "What is the hill?" ...But when it's higher up you're already living on the hill" (Interview, Male, Cerro Ramadita).

"I have to go all the way down below, because I a health check-up down there [in a polyclinic in the plain]" (Interview, Female, Cerro Las Perdices).

The "plain/below" and the "hill/above" are the two dimensions, antagonistic and at the same time complementary, that are transformed into the coordinates used to identify the loci in the urban weave of housing, services and persons.

The plain appears as a spatial and socially homogeneous unit. In contrast, the hill makes a socioeconomic stratification apparent, where as one moves up to the higher elevations, the poorer sectors come into view. Generally speaking, there is a negative perception of the people who live very high up, as well as a discriminatory attitude toward them on the part of those who live farther down. 
"Because, as you know, on any hill there are...just a handful of persons of our same human calibre, but as there are many more who come down from much higher up who are bad people" (Interview, Female, Cerro Yungay).

"It's quiet [here]; I don't have dealings with the ones from over there below, because they have a very prideful way of life. I like people who are more dynamic, more open; not those people who act haughty, when in fact they're practically on the same level as you are, just because they have children with good jobs and they have social standing, and therefore they're superior and look down on other people. Here I live happily ... up here, I've lived all my life here on the hill" (Interview, Female, Cerro Las Perdices).

In Valparaiso one can live down below on the plain, or up above on the hills; one can live farther up or farther down. Different forms of socialization and social networks correspond to these idiosyncratic topographical strata.

According to the narratives, the category of neighborhoods is often associated to the hills, characterising it with many other positive meanings. This perception comes from a combination of characteristics, such as community ties and bonds of friendship and solidarity among neighbors that constitute an essential support for the lives of senior citizens. Living in the hills becomes an inductor of social identity; people recognize and reaffirm themselves through their neighborhood. Thus the hill delimits a space where places and meanings are shared; people meet on the street and get together to establish permanent relationships.

"For example, I came to this hill at the age of $22 \ldots$ here in a house that's all broken down and decrepit and so on, but if they move me from here I'll die; imagine, more than 60 years here, living in the same neighborhood, on the same hill. I love it, it doesn't matter if the houses aren't so pretty any more because you get used to it" (Focus group, Female, Cerro Alegre).

The value given to the community dimension is an incentive for a positive perception of living in the hills. The hill assumes a positive dimension when compared to the plain, which is seen as a space where people lose their community networks, often a source of mechanisms for reciprocal solidarity and support networks.

“....All the people in the plain work and arrive home in the evening or late at night, while there is more family life in the hills, neighbours are closer to each other...among the people who live in the hills there is more communication, people get together more often, there are sports clubs, neighborhood associations, so many activities. So people meet on the corner or get together in their houses, there is more activity than in "the plain", because here [in the plain] sometimes you don't even know who lives next door, you never talk, but up there almost everybody knows each other. They get together for one reason or another (Narrative, Male, Commercial Sector, El Plan).
Knowing each other personally or being familiar to someone are factors that make older adults feel safer living in the hills.

"The other thing is the spirit of solidarity that people have here on the hill, that is something important; I think that people settle here, there are lots of people with families, they feel more secure, too" (Narrative, Female, Cerro Barón).

According to the narratives, living in the hills enables them to enjoy a better quality of life, as it is healthier in both social and physical terms. Going down to the plain on foot is considered an exercise to stay in good physical shape. The less contaminated air, the lighter vehicular traffic and the views are much-prized elements.

"Right, because the hills are better because of the air, the sunlight, because the houses down below are dark and up in the hills there aren't a lot of factors that work against you, and so.... Up above, people breathe good air, enjoy good sun" (Narrative, Female, Cerro Merced).

"The positive thing about living on the hill is the view, there's not so much noise or smog as in the plain; because in El Plan there are so many vehicles you can hardly talk...you can't even hear" (Narrative, Female, Cerro Barón).

While the hills are generally perceived as safer and healthier, the plain is seen as more comfortable and functional for older adults, mainly because of the possibilities for moving around.

"I preferred [the plain] because of the easy access, because it had access to everything. I have asthma, so climbing up and down steps - better said, staircases - as happens in Valparaiso isn't the best for living. No way. And so, right there, in that sense the road was clearly marked toward accepting wherever there was no such inconvenience" (Narrative, Male, Barrio Almendral).

“...That was obvious, that I was going to prefer living in the plain; it's more comfortable. The hill only has one bus, one taxi service. On the contrary, here on the plain all the buses, the taxis are useful for me" (Narrative, Male, Barrio Almendral).

Collective and public spaces are mainly located on the plain. Clubs and city squares are important for establishing different kind of networks that operate to the benefit of senior citizens. Many of the surveyed subjects participate in groups formed either privately as pensioners' clubs, by the companies where they used to work, or under the auspices of the Church. The perception that they have of clubs is entirely positive and these are validated as meeting and ludic spaces that have brought positive changes to the lives of Valparaiso's senior citizens.

It should also be noted that, besides the ability to socialize and endure moments of solitude, in some cases to be a member of a group implies certain material benefits, such as food, small goods or monetary loans. Likewise, access to and use of certain 
public spaces means an opportunity for senior citizens to carry out some productive, largely informal activities that can allow them to feel active and generate a small income.

"El Tata" (70) works from 8 to 9 hours a day as a peddler of coffee and small goods.

"I work here everyday starting at 7 a.m...I only rest for an hour when I go home for lunch...I have a super happy life. I have been in this Plaza for 4 years and my clientele have always been loyal to me. I make $15,000^{2}$ pesos a day. It is my way of living..." (Interview, Male, Plaza O'Higgins).

"Ramón" (63) is a retired man who spends many hours every day in Plaza O'Higgins managing a card-playing club without earning any income for this activity. Even though the Club's main purpose is to meet and play "brisca" (a traditional card game), it also functions as a cooperative that lends money to club members in need.

"This is the older adults' brisca club. We founded it on the 29th of January, 2000. There are two other brisca clubs here on this Plaza. We start at 10:30 a.m. until around 8:30-9:00 p.m.... Some of us are very good friends; there are 61 men and three women. We have social activities like short outings, lunches and dinners" (Interview, Male, Plaza O'Higgins).

"Olga" (87) is recognized by other older adults as a main character in the Plaza. She joins her friends there almost everyday to chat, pray or perhaps sell some goods.

"What I can tell you about Valparaiso is that I walk across the city everyday. I go to the Plaza to talk to my friends or maybe receive a religious teaching.... I also visit the Port, the market, Plaza Victoria, the church or the bus terminal. If I find friends in those places I stay to chat with them; if not, I just like to watch the people who come and go; they are so diverse, I like that...I generally walk to all these places, but sometimes, when it isn't too expensive for me, I take a bus..." (Interview, Female, Plaza O'Higgins).

As we can see in these statements, collective and public spaces in the plain constitute an enormous source of social capital networks and appropriate scenarios in which to assume social roles of substantial importance for seniors.

In spite of the differences between the plain and the hills, clearly the limits between these dimensions are porous, fluid and mobile. The spatial categories are sensed as complementary and they are in constant interrelation in the representations of the subjects consulted, whether because of their antagonistic characteristics or because of their continuity and contiguity.

There is a dynamic and continuous relationship between the hills and the plain that many informants name as a determining factor in their quality of life. The urban infrastructure, the location of basic services, of public spaces and entertainment determine that, generally, displacements are articulated according to the trajectory HILLS $\rightarrow$ PLAIN.

The older adults who live in the plain may dispense with climbing up the hills, and in point of fact very few persons

\footnotetext{
2 Around US\$30.
}

state that they do this. In contrast, those who live in the hills often have to go down to the plain for a variety of reasons. The seniors who come from the hills seek the satisfaction of functional needs in the plain, as well as recreational and identitary necessities.

“...I come down from my house, I get as far as the harbour on foot, walking. I come down from my house, I walk down Uruguay [Street] up to here, until Plaza O'Higgins, and then [continue walking down] from Uruguay until I reach the market..." (Interview, Female, Cerro Merced).

“...Because almost everybody goes down to the plain; they go down to shop because the hills are very expensive" (Narrative, Female, Cerro Merced).

Despite the differences between the hills and the plain and how they relate to different social networks, the connection between them must be observed in symbolic and practical terms. As we have seen, neighborhoods appear in the narratives as unique, autonomous contexts with their own values and material practices. According to Appadurai (1996, p. 186), what defines the production and spatial appropriation of different localities in this case, the plain and the hills - is the relationship between the pre-existing contexts that neighborhoods encounter, and the ones that they create. This polarity (hills/plain) is clearly present in many seniors' perceptions and narrations of Valparaiso. In this sense, it is important to highlight the special relevance that factors such as mobility and transport acquire for older adults' quality of life in a city such as this.

\section{Valparaiso as a Heritage City}

Analysis of the narratives on the perception of the urban habitat allows us to recognize that people view the city from a double perspective: as inhabitants, and as visitors. These two points of view correspond to different visions, considerations and critical attitudes. The visitor's perspective gives them the ability to look at the city from the outside and project themselves into the image of a patrimonial Valparaiso as a new and different city. In many cases, when referring to the patrimony, they position themselves more in the collective mindset than in their life experiences, and the inhabitancy of what is patrimonial takes on a positive connotation.

The recognition of Valparaiso as a Heritage City encourages the adoption of the visitor's attitude-that of the individual who approaches the city with the projections and expectations of discovery. Thus, older adults, through a process of reassigning meaning to the urban space where they have spent their entire lives, are able to take a new look and project themselves into the image of Valparaiso's heritage as something new and distinct. When these people refer to heritage, in many cases, they often speak more from their imagination than from experience, and the fact of living in a heritage site becomes and takes on a positive connotation and is an incentive for them to appropriate it, to "feel oneself as part of it." This new perception in the elderly arouses an unwonted interest in discovering or rediscovering the city, motivating them to learn about new routes or incorporate these into their daily movements around the city. 
"Well, I think that the fact that Valparaiso has been declared a World Heritage city makes us feel pleased and committed to [it]. As older people we are always complaining about having to climb the hills, about the street lighting, about the dogs - a tremendous problem, not just in the high part but in the low part as well - and this is why people feel a commitment. It's nice that people come from other places to see a certain site because it is part of the World's Heritage, to see that there is a heritage that belongs to everybody; that's nice" (Narrative, Female, Commercial Sector, El Plan).

Likewise, appreciation of heritage does not hide the morphological or infrastructure limitations of the city; however, from the visitor's perspective, the picturesque element seems to prevail over the functional. The limitations become tourist attractions, a source of pride for those who live there.

"I think this is what everybody likes about Valparaiso. That the streets are so difficult to walk on, they are hard to climb, but that is the attraction, that's why it is pretty ... so I think that it's difficult to change, because Valparaiso would lose all its charm; if you changed the streets, if you modernized them, you would change the whole structure and Valparaiso is like that, it's beautiful just as it is, even if it's difficult going up and down the hills sometimes, but that is what people notice, what they like" (Narrative, Female, Commercial Sector, El Plan).

However, when they talk about living in the city from the viewpoint of their daily routine, they identify the difficulties of access, traffic, and public transport that characterize the urban space and intervene in seniors' use and experience of the city. From the residents' perspective, the picturesque aspects linked to Valparaiso's morphology acquired a negative cast. The structural deterioration, the poor quality of the streets and the inadequate repair and maintenance are the aspects that older people identify as the most problematic, since they give rise to physical risks for people using the urban space.

"We're getting older and the condition of the city and the streets gets worse and worse...you cannot walk properly and you stumble...you just fall over" (Narrative, Female, Cerro Barón).

Moreover, the dynamics associated to tourism flows and the arrival of new inhabitants drawn to the city by its heritage value, especially to the most typical hills, bring with them effects that threaten the senior adults' quality of life. Places rapidly acquire new and transformative connotations. Attempts are made to promote a new image of the city to meet the requirements of young, dynamic people in search of entertainment and a new aesthetic. This is why, in some neighborhoods, the phenomenon of gentrification brings with it a feeling of absence of past, loss of the communitary and identitary dimensions, in which the people who remain behind are rather more perceived as residual elements of an era already ended. These processes of change negatively affect older adults, whose quotidianness - as we have already seen - is more linked to the neighborhood, to its memory and to the socialization that this memory helps to achieve.
"This neighborhood is peaceful, really peaceful, but it bothers us that they've built the hotels, because before it used to be an alleyway and people would come together and chat ... but it happened that people started putting their houses up for sale, and [other people] built buildings and blocked out everything-before we could see the sea, the lights ..." (Narrative, Male, Cerro Bellavista).

"Yes, and I went to Cerro Alegre to live, in Higuera Alley... which at the time was the most "high class," the coolest place there was, and now it's become a dump.... Isn't it amasing how things change, just incredible" (Interview, Female, Cerro Florida).

\section{Conclusions and policy recommendations}

Rapid aging population processes in both industrialized and less-industrialized urban contexts have set new challenges for policy makers and local and international urban development agendas. Especially since 2003, policy efforts have been made in some industrialized cities to project and meet seniors' needs. Nevertheless, in other world regions such as Latin America, cities face major economic, social and institutional difficulties in implementing inclusive and protectionist urban policies for this age group. Despite the existing differences between cities in the North and the South, problems related to older adults' quality of life remain a major concern for local governments. Pending aspects, such as health, housing, transport and retirement systems, are the most visible ones; however, this study suggests further important issues that must be taken into account in providing sustainable and friendlier environments for aging populations.

Our research results show the relevance of spatial and territorial factors as crucial aspects that intervene in senior adults' perception of quality of life. Social networks, identity and the agency processes of this age group are crucial issues mediated by spatial perception, use, appropriation, segregation, accessibility and mobility.

The city is experienced by the older adults from a double perspective: as the physical place where they live, and as the heritage site that is recognized worldwide. The urban habitat thus assumes different connotations, depending on the perspective from which the subject's look is emplaced. As a heritage city, Valparaiso is invested with positive attributes that emphasise the picturesque aspects of the urban structure and make one wish to get acquainted with the city through the tourist's eyes. Nevertheless, from the inhabitants' perspective, Valparaiso becomes a city with many structural deficiencies that are lived as dangers for the older adult's physical safety, as he/she moves through its precarious streets.

The city's morphology, with its characteristic division between the plain and the hills, is also experienced from a double perspective. Although the physical condition proper to the senior adult's age poses difficulties for moving between the plain and the hills, the latter are charged with positive meanings as the place where the dimension of community enables the weaving and sustaining of the human relations 
that constitute a fundamental support for the life of the older adult.

In the case of Valparaiso, the city's topography as well as its cultural patrimony constitute two main referents over which older adults - both men and women - build their sense of community and exercise different social roles that are pivotal for their subsistence and well-being (i.e., economic and recreational activities). The notion contained in the interview accounts of the use that older adults make of the neighborhood illustrates this aspect. It is linked to specific morphological parts of the city - the hills - and their connotation with positive contents related to social, environmental and physical factors, and to the landscape. In the hills, it is from the dimension of the neighborhood's life that older adults bolster their bonds of friendship and solidarity with their neighbors.

The plain, represented as a more impersonal place characterized by a more hectic pace of life, contrasts with the hills, which are described in the narratives as ideal niches for vicinity and solidarity among older adults. The plain is lived as the space of anonymity. In it, the older adult loses his/her own identity and is perceived solely and generically on the basis of his/her age. The plain, for older adults, would seem to be somewhat similar to a "no place" (Augé, 1992); that is, a place where the individual does not have a specific space. The plain subjects the older adult to the vulnerability of invisibility, in contraposition to a neighborhood-hill, which is experienced as a space of recognition, of community ties and, therefore, as a safer and healthier place.

The dimension of the hills helps to maintain the personal bonds built up through to lifetime and give older adults a sensation of continuity with the past. Even so, generational change, as well as the gentrification associated to the patrimonial dynamic, is experienced as a phenomena that bring about the alteration or dilution of the sentiment of vicinity proper to the hills. It is nonetheless important to note that, although informants' narratives might express hill/plain divergences and polarities, seniors also experience the hills/plain interdependent, mutually constitutive relationship as a fluid continuity that structures vital networks and symbolic relations.

Hills and plain thus become two spatially complementary entities to which different forms of socialization are associated. While in the hills seniors find the possibility of preserving their personal and familial identity and history, the recreational spaces located principally in the plain, such as senior clubs and city squares, make it possible for them to weave new networks based on personal and age affinities, offering them the possibility of building a new identity as mature individuals. In these spaces, older adults seem to fully assume their new life condition and validate themselves as persons in the dimension of the present, without needing to continually relate to others with the roles of the past.

Valparaiso's irregular topography, which could be considered as a negative factor in the older adult's quality of life, turns out to be an advantage for achieving a more friendly and sustainable city. In contrast, the plain does not deliver this wealth of community life.

In Valparaiso, a city with the highest aging rate of the three major cities of Chile, policies of sustainability and inclusion of all age groups - especially of older adults - must take into account the importance of spatial appropriation, use, accessibility and the benefits of heritage conditions. Social constructions of space by senior citizens emphasise collective and public spaces (in both hills and plain) as sites where social capital networks are constituted and recreated with great potential for the enhancement of their quality of life and well-being. This argument can be valid in other city contexts, where policy formulation processes intend to provide equal opportunities to all age groups in order to make our cities more sustainable, productive and democratic.

These perceptions by older adults of the advantages and disadvantages of the various parts of the city are a diagnostic, performed by the affected individuals themselves, of the effects (whether positive or negative) on their quality of life. Said diagnostic should constitute an agenda for proposing future urban and social policies aimed at guaranteeing the right to a friendlier and more inclusive city for the population as a whole, and particularly, for this age group.

In general, it can be inferred that the most critical problems (poverty, urban segregation, deficit of public transportation, accessibility, quality of the streets and their maintenance and repair, lack of street lighting, deficiencies in equipment and urban services, civil insecurity, physical risks, environmental contamination, gentrification) are the incumbency of the authorities, national and/or local, and can be rectified through public policies whose implementation depends on political will. Historically there has been a lack of management and planning on the part of the public entities in this sense. Consequently, a wide gamut of needs is available for the implementation of actions that could improve older adults' quality of life.

In the face of demographic transition and the aging of the present population, it becomes imperative - in effect, a social necessity - to prioritise and focus policies on these problems that affect an age group in process of substantial growth. At a nationwide level, this would imply to give primacy to policies for social security, social assistance and normal and continuing education. At the local level, interventions would have to be prioritised for providing better equipment (green areas, spaces for recreation, provision of infrastructure and improvement of public transport), paving of roads and optimisation and maintenance of roadways, implementation of programs for improved security and reduced urban contamination, legislation to regulate gentrification. All this, not merely applied to contingencies, but also to educational and economic improvements in the mid- and long-term, keying actions to the more precarious and neglected urban zones.

The above would redound in the achievement of urban spaces with fewer obstacles and barriers and that would, therefore, be more secure as regards the physical integrity and movements of the age groups at greater risk.

Within this strategy, the successful fostering of synergy between the intervention by public entities and the older adults' communitarian participation in resolving their own problems would be encouraging, and could be concretized in a joint plan between the two parties.

On the other hand, among the elements that more positively influence older adults' quality of life, are the family, neighborhood, and the municipal networks. These are, in great measure, attributable to the achievements of the actors themselves. Among the elements that can be said to be characteristic features of the city are the hills, that is to say, the conformation of its neighborhoods, which offers a sense of identity and the possibility of establishing networks and social bonds. Likewise, 
its friendly, healthy spaces are communitarian dimensions that offer well-being and satisfaction. All of these are supporting factors for improved quality of life. These positive aspects need to be researched in further depth to enable the fostering, emulation and replication, in more concrete and precise terms, of the urban/social example of Valparaiso's hills in other urban zones-and even in other cities. In this way greater degrees of friendliness, inclusiveness and sustainability of cities would be achieved. The integration of this age group into more extensive and consolidated networks would also be encouraged, and, thus, their participation as more active social actors within the urban community.

Strategies of this type would stimulate the construction of societies and cities that are facilitators of their senior citizens' integration and participation, and in general terms, the construction of the functional conditions proposed by the Madrid International Action Plan, in order to respond to the challenges facing our cities due to the global trend of population aging. Nevertheless, the point must be insisted on that political will is indispensable if we are to move forward in this direction. Without legislative initiatives, focused programs and good management of the latter, significant progress will not be achieved.

\section{References}

ActivAge Consortium (2004). Active aging in Europe: Methods, policies, and institutions deliverable. Final report. [Online] Available at:. http://www. iccr-international.org/activage/en/reports.html (Accessed, June 15, 2008).

Appadurai, A. (1996). Modernity at large: Cultural dimensions of globalization. Minneapolis: University of Minnesota Press.

Ardila, R. (2003). Calidad de vida: Una visión integradora. Revista Latinoamericana de Psicología, 35(2), 161-164.

Augé, M. (1992). Los ‘No Lugares'. Espacios del Anonimato. Una antropología de la sobremodernidad. Gedisa Editorial, Barcelona $125 \mathrm{pp}$.

Bartone, C. R., Bernstein, J., \& Leitmann, J. (1992). Managing the environmental challenge of Mega-Urban Regions. Paper prepared for the International Conference on Managing the Mega-Urban Regions of ASEAN Countries: Policy Challenges and Responses. 30 November-3 December, 1992. Bangkok, Thailand: Asian Institute of Technology.

Burnett, P. (2008). The contemporary mobilities of older adults. Association of American Geographers, April 15-19, 2008. Annual Meeting AAG: Boston, Massachusetts, USA.

Celade (2007). Envejecimiento y Desafío para una sociedad de todas las edades. Informe sobre la aplicación de la Estrategia regional de implementación para América Latina y el Caribe del Plan de Acción Internacional de Madrid sobre el Envejecimiento. 2da Conferencia regional sobre envejecimiento. 4-6 December 2007. Celade, Brasilia, Brasil.

Chackiel, J. (2000). El envejecimiento de la población latinoamericana: ¿hacia una relación de dependencia favorable? Encuentro latinoamericano y caribeño sobre las personas de edad. 8-10 Septiembre, 1999. CELADE/CEPAL-FNUAP-OPS. Santiago, Chile.

Fadda, G., \& Cortés, A. (2007). Barrios. En busca de su definición en Valparaiso. Urbano, 16, 50-59.

Fadda, G., \& Jiron, P. (1999). Quality of life: A methodology for urban research. Environment and Urbanization, 2, 261-270.

Gravano, A. (2003). Antropología de lo barrial. Estudios sobre producción simbólica de la vida urbana. Buenos Aires: Espacio Editorial.

INE (2000). Chile y los Adultos Mayores en la Sociedad del 2000. Boletín Informativo del Instituto Nacional de Estadísticas. 28 de Agosto, 2000.

Lorinc, J. (2008). The aging city. [Online] Available at:. http://www. walrusmagazine.com/articles/2008.02-urban-planning-toronto- publicspace-john-lorinc-the-aging-city/ [Accessed June 16, 2008].

Moyano, E., \& Ramos, N. (2007). Bienestar subjetivo: Midiendo satisfacción vital, felicidad y salud en población chilena de la Región Maule. Universum, 22(2), 177-193.

Naciones Unidas (2002). Declaración Política y Plan de Acción Internacional de Madrid sobre el Envejecimiento. II Asamblea Mundial sobre el Envejecimiento. 8-12 Abril, 2002. Madrid: Naciones Unidas.

Organization for Economic Co-operation and Development (2005). OECD Factbook. [Online] Available at:. http://www.oecd.org/ [Accessed November 20, 2008].

Phillipson, C. (2007). The 'elected' and the 'excluded': Sociological perspectives on the experience of place and community in old age. Aging $\mathcal{E}$ Society, 27, 321-342.

Phillipson, C., Bernard, M., Phillips, J., \& Ogg, J. (2001). The family and community life of older people: Social networks and social support in three urban areas. London: Routledge.

Rueda (1998). Habitabilidad y Calidad de Vida. http://habitat.aq.upm.es.

Sargatal, M. A. (2001). Gentrificación e Inmigración en los Centros Históricos: El Caso del Barrio del Raval en Barcelona.Scripta Nova, 94 ([Online] Available at: http://www.ub.es/geocrit/sn-94-66.htm [Accessed March 12, 2008]).

Segato, R. L. (2005). En busca de un léxico para teorizar la experiencia territorial contemporánea. In D. Herrera, \& E. Piazzini (Eds.), (Des) Territrialidades y (No)Lugares: Procesos de configuración y transformación social del espacio. Medellín: INER Universidad de Antioquia.

Soja, E. (1989). Postmodern geographies: The reassertion of space in critical social theory. New York: Verso.

Victoria García-Viniegras, Carmen (2008). Calidad de Vida. Aspectos teóricos y metodológicos. Buenos Aires: PAIDÓS.

Wellman, B. (1996). Are personal communities local? A dumptarian reconsideration. Social Networks, $18,347-354$.

Zukin, S. (1992). The city as a landscape of power. In L. Budd, \& S. Whimster (Eds.), Global Finance and Urban Living. New York: Routledge. 